\title{
Specific features of psycho-emotional states of working women during pregnancy
}

\author{
Alexander V. Bulgakov ${ }^{1}$, Nigina S. Babieva², Elena A. Levanova ${ }^{3}$, Ludmila N. Gridyaeva ${ }^{4}$, Maria A. Erofeeva ${ }^{5}$, \\ Irina E. Sokolovskaya ${ }^{6}$, Liana Y. Davidyan ${ }^{7}$
}

\begin{abstract}
Objective: Specific features of the mental state of women during pregnancy have been attracting the attention of specialists for many years. The article is aimed at describing an empirical study of the identification of specific features of emotional states and self-esteem of working women during pregnancy.

Method: The leading method to investigate this problem is diagnostic and static methods, which allow one to reveal the presence of significant differences in the emotional states of pregnant women, the psychological component of the gestational dominant and self-esteem.

Results: According to the results of the empirical study, it was found that in employed women, in comparison with unemployed pregnant women, the optimal and hypogestognosic type of attitude to pregnancy is more pronounced, an average level of self-esteem is observed with a tendency to high In non-working women, it was found that, in comparison with working pregnant women, an alarming type of attitude towards pregnancy was revealed, an obsession with oneself and one's own negative experiences; uncertainty and negative emotional background were revealed in relation to the role of the mother, low self-esteem was identified.

Conclusion: In employed women, in comparison with unemployed pregnant women: 1) the optimal and hypogestognosic type of attitude towards pregnancy is more pronounced - that is, employed women have an emotionally positive sentiment, they are joyful, active and goal-oriented; 2) they like the way of life that they lead, which forms their positive mood; 3) there is a lack of support for their lifestyle from relatives and people around, which leads to the dominance of low spirits; 4) there is an average level of self-esteem with a tendency to high. It was found that in non-working women, in comparison with working pregnant women: 1) an alarming type of attitude towards pregnancy was found, an obsession with oneself and one's own negative experiences; 2) uncertainty and negative emotional sentiment in relation to the role of the mother have been found; 3 ) low selfesteem has been revealed. The results of the study can be used in practical work of maternity homes, counseling, as well as in assessing the emotional state of pregnant women.
\end{abstract}

Keywords: pregnancy, self-attitude of a pregnant woman, type of manifestation of the psychological component of the gestational dominant (PCGD), self-esteem

\section{INTRODUCTION}

It is becoming increasingly popular at present to study motherhood both in theoretical and practical aspects. In comprehensive studies of the condition of a woman during pregnancy, various factors are taken into account: personality traits, life history, adaptation to marriage, adaptability features as personality traits, satisfaction with emotional relationships with her mother, motherhood models, cultural, social and family characteristics, physical and mental health, self-esteem. Successful pregnancy correlates with successful adaptation to motherhood as satisfaction with one's maternal role, competence, lack of problems in interaction with the child.

\footnotetext{
1 Vygotsky Institute of psychology of the Russian state humanitarian University, Moscow, Russia.

2 Sechenov First Moscow State Medical University, Moscow, Russia.

3 Moscow State Pedagogical University, Moscow, Russia.

4 Voronezh State Pedagogical University, Voronezh, Russia.

5 Moscow University of the Ministry of internal Affairs of Russia V. Kikot, Moscow, Russia.

6 Moscow Institute of Economics and culture (MIEK), Moscow, Russia.

7 Ulyanovsk State University, Ulyanovsk, Russia.
}

Correspondence: Liana Y. Davidyan

Ulyanovsk State University, Ulyanovsk, Russia

E-mail:dliana2009@mail.ru

Received: 11 May 2018, Accepted: 3 Oct 2018

(C) 2018 by the authors; licensee Modestum Ltd., UK. This article is an open access article distributed under the terms and conditions of the Creative Commons Attribution License (http://creativecommons.org/licenses/by/4.0/).

Electronic Journal of General Medicine 
The study of the psychophysiological state of women during childbirth $(5,8,9,10)$ suggests that there is an inherent dynamic pattern during pregnancy with aggravations and weakening of the psycho-physiological problems of a woman.

Emotional changes of a woman while expecting a child in the first trimester of pregnancy are associated with mixed feelings and worries about the course of pregnancy. A woman notices her own changes in her habits, tastes and preferences. The emotional state of a woman can be described as an "emotional swing". The second trimester of pregnancy can be called quite contradictory emotionally. Different phenomena can be observed in every woman. One woman experiences emotional serenity, her activity, working capacity increases. Another woman has sharp changes in mood, nervousness and irritability. Some women go deep into their personality, analyze everything that happens, compare how their lives have changed, women start feeling that time is accelerating $(3,11,14,21)$.

At the beginning of the third trimester of pregnancy, the "nest syndrome" becomes pronounced, which is manifested in increased activity and an attempt to settle existing problems. The direction of activity during this period is associated with preparation for childbirth and the postpartum period. By the end of pregnancy, the psycho-emotional state of women is characterized by fear of childbirth, incompetence, and increased stress. Women experience anxiety associated with the upcoming childbirth. The situation of uncertainty dominates. There is frequently a sharp decline in one's own self-esteem and self-acceptance. The need for care and protection is increasing, sexual desire is decreasing $(7,18,22$, $23,27)$.

The anxiety and worries that a woman experiences in the third trimester of pregnancy have a negative influence on her general psycho-emotional state. It is very important for a woman to feel emotionally comfortable during this period. In addition, the sleep pattern, appetite, adequate perception of the real situation are disturbed, pessimistic thoughts prevail. Relations with others do not go well, the adequate attitude to others and to oneself is lost. A woman looks at the world with other eyes and may react inadequately to people around her, changes in her personality occur.

Anxiety plays the role of the deadly enemy, the state of things gets worse and this can cause complications in upcoming delivery. The change in the minds of women is largely due to the influence of the evolutionarily developed biological mechanisms of the mother in relation to her child (affection). An important role in the formation of attachment in the mother is played by the role of "perceptual" experience (experience associated with the mother's feeling of fetal movements, which causes the future mother to have a feeling of "unity" with her own child).

During pregnancy, women's physiological, psycho-physiological and psychological levels change. The change in these levels in domestic psychology is referred to as pregnancy syndrome. The pregnancy syndrome is a neoplasm or condition that is limited to a specific period of time, is detected at the moment when the woman realizes that she is pregnant and it flows into the moment of her child's pygmalionization $(4,6,12,16,20)$.

The pregnancy syndrome is experienced by a woman at an unconscious level, has certain time limits and is characterized by the following symptoms (2).

At the first stage, the woman realizes her own pregnancy. The peculiarity of this stage is that the higher the level of intellectual development of a woman is, the higher the degree of her self-activation and social status in society, the harder it will be for her to become a mother.

The next stage in the development of the pregnancy syndrome is the reflexive acceptance of a new personal image: "I am pregnant". This stage is characterized by the recognition of physiological changes in the body. The real biological and neuroendocrine changes that accompany pregnancy can have a profound psychological effect $(13,15,17,26)$.

The symptom of emotional lability should be noted in particular, which, to some or another extent, is inherent in the entire period of pregnancy. This implies a symptom of emotional maladjustment, which manifests itself in fluctuations in the mood. In some women, passivity increases, and a feeling of higher satisfaction and pleasure arises. Others experience mild depression and increased physical activity. Mood swings can be expressed in varying degrees of internal tension, a feeling of boredom, sluggishness, growing dissatisfaction with oneself, a verbalized feeling of depression.

A woman's awareness of her own pregnancy is also expressed in the symptom of conflicting attitudes towards pregnancy. At this time, there are fast mood swings in the emotional sphere, experience, anxiety, combined with joy, cheerfulness. Belief in the better, impatient expectation of the time when a child will be born is associated with an experience of fear of the upcoming delivery, an experience of a material state, etc $(19,24,25,28)$.

The process of the mental identity of a woman comes next when a woman realizes that she is the carrier of a new life. This happens when the baby begins to turn in the womb. A woman feels a surge of the female energy and a charge of inspiration. 
Table 1: Differences in attitude of a pregnant woman to herself on the basis of Dobryakov's technique "TPWA" with the use of the Mann - Whitney criterion

\begin{tabular}{lcccccc}
\hline Indicators & UPW & U emp & WML & Uэмп & EPW & Uemp \\
\hline Attitude to pregnancy & 1.8 & 2 & 6 & 5 & 11 & 7 \\
\hline Way of life & 2 & 1 & 7 & 6.5 & 6 & 0 \\
\hline Attitude to childbirth & 3 & 0.5 & & 7 & 2 \\
\hline
\end{tabular}

Thus, the syndrome of pregnancy is typical for all women during pregnancy. However, its symptoms are expressed in each woman individually. Most clearly the abovementioned symptoms, reinforced by the fear of the unknown, appear during the first saved pregnancy.

\section{MATERIALS AND METHODS}

Based on the foregoing, one can say that a woman's pregnancy is a qualitatively new state of the woman's body and psyche. A pregnant woman goes through a series of physiological and mental stages that change her body and personality as well. It is very important to understand and know that the health of the unborn child depends on how pregnancy goes.

The aim of our study was to study specific features of the psycho-emotional state of employed women during pregnancy. We assumed that women who work and do not work during pregnancy have particular psycho-emotional states.

To verify the hypothesis, we used the following research methods:

1. Psychodiagnostic instruments:

- Test-questionnaire to determine the level of self-esteem (S. Kovalev);

- Test of a pregnant woman's attitudes "TPWA" (Dobryakov).

2. Statistical methods.

The study was conducted at the Regional Prenatal Center in Moscow; the sample was represented by 95 women pregnant for the first time in the 2nd and 3d trimester, aged between 24 and 37, of them 35 employed women, 30 unemployed women and 30 women on maternity leave.

\section{RESULTS}

At the first stage of processing empirical data of Dobrykov's test of a pregnant woman' attitudes the following results were found (Table 1).

Further in the text and in the tables the following abbreviations will be used:

- Employed pregnant women - EPW;

- Unemployed pregnant women - UPW;

- Women on maternity leave - WML.

The data obtained indicate that differences in attitudes towards pregnancy in women of the three groups were not found (Table 1). For example, in unemployed women and women on maternity leave $U$ emp. $=2$ (the index is in the zone of insignificance). In women on maternity leave and employed pregnant women $U$ emp. $=9$ (the index is in the zone of insignificance). Employed pregnant women and unemployed women had $\mathrm{U}$ emp. $=8$ (the index is in the zone of insignificance). The way of life scale for unemployed and women on maternity leave gave $U$ emp. $=1$ (the index is in the zone of insignificance). In women on maternity leave and employed pregnant women $U$ emp. = 11 (the index is in the zone of insignificance). Employed pregnant women and unemployed women had $\mathrm{U}$ emp. $=0$ (the index is in the zone of insignificance).

The attitude towards childbirth among unemployed and women on maternity leave showed $\mathrm{U}$ emp. $=0.5$ (the index is in the zone of insignificance). Women on maternity leave and employed pregnant women had $U$ emp. $=6.5$ (the index is in the zone of insignificance). Employed pregnant women and unemployed women had $U$ emp. $=2$ (the index is in the zone of insignificance).

The obtained results presented in Table 2 indicate that the attitude to oneself as a mother in unemployed women and women on maternity leave is $\mathrm{U}$ emp. $=10$ (the index is in the zone of insignificance). Women on maternity leave 
Table 2: Differences in a pregnant woman's attitude to herself on the scale "Mother-child" on the basis of Dobryakov's "TPWA" technique with the use of the Mann-Whitney's ctiterion

\begin{tabular}{lcccccc}
\hline Indicators & UPW & Uemp & WML & Uemp & EPW & Uemp \\
\hline Attitude to oneself as a mother & 2.25 & 10 & 5.3 & 39 & 11 & 22 \\
\hline Attitude to a child & 2.25 & 20 & 5.3 & 48 & 7 & 17 \\
\hline Attitude to breastfeeding & 2.25 & 11 & 5.3 & 49 & 6.5 & 14 \\
\hline
\end{tabular}

Table 3: Differences in a pregnant woman's attitude to people around on the basis of Dobryakov's "TPWA" technique with the use of the Mann-Whitney's test

\begin{tabular}{lcccccc}
\hline Indicators & UPW & Uemp & WML & Uemp & EPW & Uemp \\
\hline Relatives' attitude to a pregnant woman & 2 & 15 & 5 & 20 & 5 & 34 \\
\hline A husband's attitude to a pregnant wife & 2 & 12 & 5 & 22 & 6 & 45 \\
\hline Strangers' attitude to a pregnant woman & 2.5 & 6 & 5 & 14 & 6 & 41 \\
\hline
\end{tabular}

Table 4: Differences in expressiveness of the type of psychological component of gestational dominant (PCGD) based on Dobryakov's "TPWA" with the use of the Mann - Whitney test

\begin{tabular}{lcccccc}
\hline Indicators & UPW & Uemp & WML & Uemp & EPW & Uemp \\
\hline Optimal & 2.1 & 52 & 7.4 & 202 & 10.9 & 45 \\
\hline Euphoric & 0.59 & 45 & 5.9 & 179 & 5.9 & 24 \\
\hline Hypogestognosis & 1 & 53 & 3.8 & 247 & 6.8 & 2 \\
\hline Anxious & 1.49 & 34 & 4.9 & 153 & 13 \\
\hline Depressive & 0 & 0 & 2.4 & 222 & 0.25 & 0 \\
\hline
\end{tabular}

and employed pregnant women had $\mathrm{U}$ emp. $=39$ that is the zone of significance in which significant and reliable differences were found. Employed pregnant women and unemployed had $\mathrm{U}$ emp. $=22$ (the index is in the zone of insignificance).

The attitude to a child among unemployed and women on maternity leave was $\mathrm{U}$ emp. $=20$ (the index is in the zone of significance, there are significant differences). Women on maternity leave and employed pregnant women had $\mathrm{U}$ emp. $=48$ (the index is in the zone of significance, significant differences were found). Employed pregnant women and unemployed women had $U$ emp. $=17$ (the indicator is in the zone of insignificance).

The attitude to breastfeeding among unemployed and women on maternity leave was $U$ emp. $=11$ (the index is in the zone of insignificance). Women on maternity leave and employed pregnant women had $\mathrm{U}$ emp. $=49$ (the index is in the zone of significance). Employed pregnant women and unemployed women had $\mathrm{U}$ emp. $=14$ (the index is in the zone of insignificance).

Proceeding from the data obtained as a result of mathematical analysis (Table 3), the attitude of relatives to pregnant women among unemployed women and women on maternity leave is equal to $\mathrm{U}$ emp. $=15$. This index of the criterion is in the zone of significance. Women on maternity leave and employed pregnant women have $U$ emp. $=20$ (the index is in the zone of insignificance). Employed pregnant women and unemployed women have $\mathrm{U}$ emp. $=34$ (the index is in the zone of significance).

On the scale of a husband's attitude to a pregnant woman in unemployed women and women on maternity leave was at $\mathrm{U}$ emp. $=12$ (the index is in the zone of insignificance). Women on maternity leave and employed pregnant women have $U$ emp. $=22$ (the index is in the zone of insignificance). Employed pregnant women and unemployed pregnant women have $\mathrm{U}$ emp. $=45$ (the index is in the zone of significance). The results on the scale of strangers' attitude to pregnant women among unemployed women and women on maternity leave were $U$ emp. $=6$ (the index is in the zone of insignificance). Women on maternity leave and employed pregnant women had $\mathrm{U}$ emp. $=14$ (the index is in the zone of insignificance). Employed pregnant women and unemployed women had $\mathrm{U}$ emp. $=41$ (figure is in the zone of significance).

We also examined the level of expressiveness of psychological component of gestational dominant.

The results of the data obtained, based on mathematical analysis (Table 4), indicate that:

- The level of optimal PCGD for unemployed women and women on maternity leave was at U emp. = 52 (the index is in the zone of significance), there are significant differences. Women on maternity leave and employed pregnant women have $U$ emp. $=202$ (the index is in the zone of insignificance). Employed pregnant women and unemployed pregnant women have $\mathrm{U}$ emp. $=45$ (the index is in the zone of insignificance). 
Table 5: Comparison of the pregnant women's self-esteem level based on S.V Kovalyov's technique with the use of the Mann-Whitney's criterion

\begin{tabular}{lcccccc}
\hline Indicators & UPW & U emp & WML & U emp & EPW & U emp \\
\hline Level of self-esteem & 65 & 32 & 65 & 57 & 40 & 30 \\
\hline
\end{tabular}

- The euphoric type of PCGD for unemployed women and women on maternity leave was at $U=45$ (the index is in the zone of insignificance). Women on maternity leave and employed pregnant women have $U$ emp. $=179$ (the index is in the zone of significance). Employed pregnant women and unemployed pregnant women have $U$ emp. $=24$ (the index is in the zone of insignificance).

- The hypogestognosic type of PCGD in unemployed pregnant women and women on maternity leave was at $U$ emp. $=53$ (the index is in the zone of significance). Women on maternity leave and employed pregnant women had $\mathrm{U}$ emp. $=247$ (the index is in the area of significance). Employed pregnant women and unemployed pregnant women had $\mathrm{U}$ emp. $=61$ (the index is in the zone of significance).

- The anxious type of PCGD in unemployed pregnant women and women on maternity leave was at $\mathrm{U}$ emp. $=34$ (the index is in the zone of insignificance). Women on maternity leave and employed pregnant women had $\mathrm{U}$ emp. $=153$ (the index is in the zone of significance). Employed pregnant women and unemployed pregnant women had $\mathrm{U}$ emp. $=13$ (the index is in the zone of insignificance).

- The depressive type of PCGD for unemployed pregnant women and women on maternity leave was at $U$ emp. = 0 (the index is in the zone of insignificance). Women on maternity leave and employed pregnant women $\mathrm{U}$ emp. $=222$ (the index is in the zone of insignificance). Employed pregnant women and unemployed pregnant women had $\mathrm{U}$ emp. $=0$ (the indicator is in the zone of insignificance).

- The following results were obtained at the second stage of processing empirical data based on S.V. Kovalev's testquestionnaire of the self-esteem level.

The level of self-esteem in unemployed pregnant women and women on maternity leave shows $\mathrm{U}$ emp. $=32$ (the index is in the zone of insignificance). The level of self-esteem in women on maternity leave and employed women had $\mathrm{U}$ emp. $=57$ (the index is in the zone of significance), significant differences were found.

\section{DISCUSSION}

Discussion of the results of "The attitude of a pregnant woman to herself" based on Dobryakov's "TPWA" technique.

Employed pregnant women in the third and second trimester show a high index on the scale "attitude to pregnancy", women are positive about pregnancy, pregnancy is often desired, which arouses extremely positive emotions in them. Unemployed pregnant women and women who are on maternity leave feel well in the second and third trimesters, they are still mobile and active, despite the fact that the number of social contacts has decreased.

According to the way of life scale, working pregnant women have a high index in the second and third trimester. From the obtained results it follows that women experience positive emotions, and their joy increases when the moment of child birth is approaching, preparing for childbirth, women like pregnancy, and despite their particular position their way of life has not actually changed. Unemployed women and women on maternity leave during the second and third trimester have low rates. Such results suggest that they do not accept themselves, they are dissatisfied with themselves and their bodies.

Discussion of the results "Mother-child" based on Dobryakov's "TPWA" technique

The scale - the attitude to childbirth. Employed pregnant women in the third trimester had the highest point. Here we can speak about the desirability of pregnancy and its positive course. Employed women in the second trimester showed an average index. That is, women who have not gone on maternity leave have a very positive attitude towards childbirth by the end of pregnancy, they are in a state of excitement, in joyful anticipation of an early meeting with the baby. Women on maternity leave show a slightly high index in the second trimester and, accordingly, demonstrate less anxiety. Women who are on maternity leave had an average score point during the third trimester. This may indicate that they are very positive about childbirth, and may have a slight anxiety. The average index in unemployed pregnant women in the second and third trimester is low. That is, at the time of delivery the emotional sentiment is going down in unemployed women. Employed pregnant women in the second trimester had a high index. They believe that 
motherhood is their element, they attend prenatal training courses, read useful literature, want to know everything about motherhood.

Women on maternity leave in the second and third trimester showed indices of almost the same level, it follows from this that women are worried about motherhood and are not completely confident in their competence. Unemployed pregnant women in the second and third trimester have the same number of points - a low level. Women from this group are very worried about the course of pregnancy, the attitude towards themselves as a future mother has not clearly been formed, they are very worried that they will not cope with the role of the mother.

Discussion of the results of "Attitude of a pregnant woman to people around them" based on Dobryakov's "TPWA" technique.

The first scale is the attitude of a husband to a pregnant woman. The index of employed women in the second trimester is at an average level - the woman still leads an active way of life, busy with her work. The emotional sentiment is elevated. Employed women in the third trimester had a high index. This suggests that the spouses' relations are developing well, the soon-to-be father also takes part in the parental development much more actively than he did in the second trimester. Women on maternity leave in the second trimester show an average index, which indicates their well-being in the family life. Women on maternity leave in the third trimester have a slightly high index. Unemployed pregnant women have a low index in the second and third trimester, a husband's attitude to a pregnant woman is not always unequivocal. Pregnancy often becomes a means of manipulating the husband, the desire to change the relationship with the spouse in her favor. The mood is lowered, the woman is often upset for various reasons and feels dissatisfaction with life.

The scale: the attitude of relatives to a pregnant woman.

In employed women, in the second and third trimester, the indices differ slightly: in the third trimester, the index is higher, as the woman needs more attention in late pregnancy, she needs the support of her close relatives. Women on maternity leave in the third trimester also have a slightly high index than in the second trimester. Unemployed women in the third and second trimester have the same indices, which suggests that the emotional sentiment of such women is lowered, they have much more negative experiences.

The scale of strangers' attitude to a pregnant woman.

In employed pregnant women, the index in the third trimester is high - women are among other people and their pregnancy is hard to miss, they get a positive response from the people around, which gives them joy. In the second trimester, the index is lower, since not all people around her notice her special condition and not all are nice to a future mother. Unemployed pregnant women demonstrate low indices.

Discussion of the results of the expressiveness type of psychological component of gestational dominant (PCGD) based on Dobryakov's "TPWA" technique.

The optimal type of PCGD is the most popular. Employed women have high indices of this type in the second and third trimesters. In women on maternity leave, average indices are observed in the second and third trimester. Unemployed pregnant women in the second and third trimester showed a low index and the lowest value.

The hypogestognosic type of PCGD is found in unemployed women. Most often, it is accompanied by such types of family upbringing as hypoprotection, emotional rejection, and underdevelopment of parental feelings.

The euphoric type of PCGD is the most popular among employed women in the third trimester. The anxious type of PCGD is more common in women who are on maternity leave in the third trimester. The depressive type of PCGD is the least common.

\section{CONCLUSION}

Based on the results of the study, we can conclude that euphoric types are the most frequent and optimal among employed women. In the category of unemployed pregnant women and women on maternity leave, such types as hypogestognosic, anxious, and depressive types are more common.

Self-esteem of employed pregnant women has the following features: in the second trimester, working women have the following levels of self-esteem: high level $-8 \%$, average level $-84 \%$, and low level $-8 \%$. In the third trimester, employed women have an average level at $76 \%$ and a low level of self-esteem at $24 \%$. Women on maternity leave have a low level of self-esteem (87\%), an adequate level of self-esteem - 13\%. Unemployed pregnant women in the second trimester in $50 \%$ demonstrate an average level of self-esteem and in $50 \%$ a low level of self-esteem. Unemployed pregnant women in the third trimester in $100 \%$ of cases demonstrate a low level of self-esteem. 
The results of the empirical study permit us to draw the following conclusions: in employed women, in comparison with unemployed pregnant women:

1) the optimal and hypogestognosic type of attitude towards pregnancy is more pronounced - that is, employed women have an emotionally positive sentiment, they are joyful, active and goal-oriented;

2) they like the way of life that they lead, which forms their positive mood;

3) there is a lack of support for their lifestyle from relatives and people around, which leads to the dominance of low spirits;

4) there is an average level of self-esteem with a tendency to high.

It was found that in non-working women, in comparison with working pregnant women:

1) an alarming type of attitude towards pregnancy was found, an obsession with oneself and one's own negative experiences;

2) uncertainty and negative emotional sentiment in relation to the role of the mother have been found;

3) low self-esteem has been revealed.

Thus, the hypothesis that the psycho-emotional sentiment will be positive during pregnancy in working women in comparison with unemployed women who will have a more anxious state to prevail, has been confirmed.

\section{REFERENCES}

1. Batuev AS. Psychophysiological nature of the dominant maternity. Psychology today. Yearbook of the Russian Psychological Society. 1996;2(4):69-70.

2. Bazhenova OV, Baz LL, Kopyl OA. Readiness for motherhood: the allocation of factors, the conditions of psychological risk for the future development of the child. Synapse. 1994;4:35-42.

3. Bowlby D. Maternal care and mental health. Moscow: Publishing Urao; 2005.

4. Brusilovsky Al. Life before birth. Moscow: Knowledge; 2001.

5. Brutman VI. Early social orphanhood. Moscow: Independent Association of Child Psychiatrists and Psychologists; 1994.

6. Brutman VI. Deviant maternal behavior. Moscow psychotherapist. 1996;4:81-98.

7. Brutman VI, Enikolopov SN, Radionova MS. Unwanted pregnancy in victims of sexual violence (psychological and psychiatric aspects of the problem). Questions of psychology. 1995;1:33-40.

8. Brutman VI, Radionova MS. Formation of mother's attachment to the child during pregnancy. Questions of psychology. 1997;7:38-47.

9. Brutman VI, Varga AY, Khamitova IYu. The influence of family factors on the formation of deviant behavior of the mother. Psychological Journal. 2000;21(2):79-87.

10. Bulgakov AV, Surkova LM. Professional competence of the psychologist-perinatologist. Moscow: Izd. Journal of "Practical Psychology and Psychoanalysis"; 2004. PMCid:PMC518851

11. Filippova GG. Maternity: a comparative psychological approach. Psychological Journal. 1999;20(5):81-88.

12. Filippova GG. Psychology of motherhood. Moscow: Medicine; 2002. PMCid:PMC379141

13. Ivanova AA. Organization of work with pregnant women in the framework of antenatal training. Kaluga: Trust; 2014.

14. Kon IS. Child and society. Moscow: Pedagogy; 1988.

15. Kopyl OA, Baz LL, Bazhenova OV. Readiness for motherhood: the allocation of factors, the conditions of psychological risk for the future development of the child. Synapse. 1993;4:35-42.

16. Kosheleva AD, Alekseeva AS. Diagnosis and correction of maternal relationships. Moscow: Family Research Institute; 1997.

17. Louis G, Margolis E. The motherhood report: How women feel about being mothers. New York: Routledge; 1987.

18. Meshcheryakova SYu. Psychological readiness for motherhood. Questions of psychology. 2000;5:18-27.

19. Narcissova GP. About motherhood. Moscow: AKADEMA; 2015.

20. Pernu LD. (2016). I'm waiting for the baby. Moscow: Medicine; 2016.

21. Raphael-Leff J. Facilitators and regulators: Two approaches to mothering. Brit. Journal Medicine Psycological. 1983;56(4):379-390. https://doi.org/10.1111/j.2044-8341.1983.tb01571.x 
22. Shcherbakova OI, Chernykh AK, Balahanova DK, Midova VO. Stress control practices for mental balance improvement in academic sports. Teoriya i Praktika Fizicheskoy Kultury. 2018;9(1):22-23.

23. Shcherbakova OI, Formation managers stress management skills. Modern training and coaching: new opportunities in business and education. Moscow: Russian University of Economics; 2017.

24. Skoblo GV. Phenomenology and genesis of postpartum maternal depressions. Mental health issues in children and adolescents. 2004;1:22-28.

25. Vanyukhina NV. Features of mental states of pregnant women and childbirth. Psychology of mental states. 2016;7:216-218.

26. Wieder S. Identifying the multy-risk family prenatally: Antecedent psychological factors and infant developmental trends. Infant-Mental Health Journal. 1987;4(3):165-201. https://doi.org/10.1002/10970355(198323)4:3<165::AID-IMHJ2280040304>3.0.CO;2-V

27. Winnicott DV. Small children and their mothers. Moscow: Independent firm "Class"; 1998.

28. Zakharova El. Conditions for the formation of a negative attitude of modern women to the maternal role. Cultural-Historical Psychology. 2015;11(1);44-49. https://doi.org/10.17759/chp.2015110106

$\diamond \diamond \diamond \diamond \diamond \diamond \diamond$

http://www.ejgm.co.uk 